\title{
Effect of epibenthic macropredators on community structure in subtidal organically enriched sediments in the inner Oslofjord
}

\author{
John A. Berge and Veronica Alvarez Valderhaug \\ Institute of Marine Biology and Limnology, Department of Marine Zoology and Marine Chemistry, University of Oslo, \\ Oslo, Norway
}

\begin{abstract}
Predator exclusion experiments were performed on an unvegetated low-energy subtidal mudflat. Exclosures were maintained for periods from 2 to 5 mo to protect infauna from epibenthic macropredators. Recruitment was studied by placing trays with azoic sediment on the bottom. Predation effects were determined by comparing faunal composition and abundance on natural sediment and in recruitment trays inside and outside the cages. Community structure was not affected by the cages. There was a tendency for several species to increase in abundance inside the cages on the natural sediment, but only a few increases were significant. Habitat modifications under the cages were small. It is concluded that in the subtidal of the Oslofjord macropredators are not important in determining community structure in sediments, and that there is only a small effect of macropredators controlling densities of infauna.
\end{abstract}

\section{INTRODUCTION}

Experimental manipulation of natural communities in the field is an important approach towards understanding the mechanisms controlling community structure. One of the most common methods used for determining the effect of predators on community structure is that of exclusion or inclusion cages. Such experiments have made valuable contributions to an understanding of the mechanisms controlling communities in sedimentary habitats (Blegvad, 1927; Naqui, 1968; Woodin, 1974, 1981; Young et al., 1976; Reise, 1977a, b, 1978, 1979; Virnstein, 1977, 1978, 1979; Young and Young, 1978; Peterson, 1979; Holland et al., 1980)

Cages, however, may do more than exclude or include predators. Different sedimentation rates inside and outside cages may affect the fauna unequally (Hulberg and Oliver, 1980). Thus 2 non-exclusive hypotheses can be proposed to explain the results:

(1) Faunal changes in cages are caused by animals responding to the change in the manipulated predation pressure.

(2) Faunal changes are caused by the animals responding to cage-induced modifications, especially sediment deposition and erosion.
In experiments in a high energy area of Monterey Bay, California (USA), Hulberg and Oliver (1980) found little support for Hypothesis 1, but strong support for Hypothesis 2; they found evidence for the sedimentary habitat being modified by the cages which resulted in an increase in polychaete densities.

The reduced water currents inside the cages result in higher sedimentation rates, whereas outside the cages, erosion is caused by increased water movements, due to diversion of water currents by the cage. The most ideal locations for avoiding these effects are, therefore, low-energy areas with little or no water currents.

Berge (1980) performed predator exclusion/inclusion experiments in the low-energy subtidal of an eutrophicated fjord, and in a non-eutrophicated mediumexposed subtidal area. Results from the eutrophicated area indicated that epibenthic macropredators are not of fundamental importance in structuring relative abundance between major animal groups. However, in the non-eutrophicated area, predation is an important factor controlling abundance of at least some faunal components. However, these experiments were not conclusive in relation to the effect of predators on abundance in the eutrophicated area because of limitations in the method adopted. The present study was 
therefore designed to elucidate further the effect of epibenthic macropredators in a low-energy, subtidal, eutrophicated habitat.

\section{MATERIAL AND METHODS}

The experiments were performed on a mudflat $\left(10^{\circ} 37^{\prime} 64^{\prime \prime} \mathrm{E}, 59^{\circ} 52^{\prime} 26^{\prime \prime} \mathrm{N}\right)$ at a depth of 22 to $23 \mathrm{~m}$ near Vassholmen in the eutrophicated inner Oslofjord, Norway. The fauna of the inner Oslofjord was recently investigated by Mirza and Gray (1981).

Pearson and Rosenberg (1978) have described the succession of macrobenthic communities along a gradient of organic enrichment. Near the enriched end of such a gradient is a point of maximum abundance of opportunistic species. The community at our experimental site would, following Pearson and Rosenberg's scheme, be positioned towards the less enriched end of the peak of opportunists, near the ecotone point (Pearson and Rosenberg, 1978). The community at the site is disturbed as the distribution of individuals per species cannot be fitted to a single log-normal distribution (Gray and Mirza, 1979).

The sediment at the experimental site is dominated by a high content of faecal pellets in the top $4 \mathrm{~cm}$ of the sediment. This implies that traditional sieving methods do not give a realistic particle size distribution for the sediment. The size distribution was therefore investigated by measuring the maximum length of 140 to 200 randomly selected particles in samples of sediment which were retained after washing on a $35 \mu \mathrm{m}$ sieve.

Carbon and nitrogen analysis of the sediment in the area was measured on a Carlo Erba Elemental analyzer model 1106. Water content of the sediment was estimated by drying the sediment at $60^{\circ}$ to $70^{\circ} \mathrm{C}$ for $48 \mathrm{~h}$.

Photographs were taken for inspection of cages and sediment during the experiments. Point measurements of salinity and temperature were made five times during the experimental period $1 \mathrm{~m}$ above the bottom.

Epibenthic macropredators were excluded from the experimental area by cages. Each cage covered $0.24 \mathrm{~m}^{2}(0.4 \times 0.6 \mathrm{~m})$ and was $20 \mathrm{~cm}$ high. The cages were made of acid-resistant stainless-steel wire mesh (square mesh size $4 \mathrm{~mm}$ ). Each cage was pushed 5 to $10 \mathrm{~cm}$ into the sediment avoiding inclusion of visible macropredators. The experimental design consisted of 2 to 3 replicate cages in three series. Each series lasted for a duration of 2 to $5 \mathrm{mo}$.

Samples for determination of abundance and faunal composition were taken by diver-operated corers (inner diameter $6 \mathrm{~cm}$ ). At the end of each experimental series 4 cores were taken inside each cage and 7 to 15 samples outside. Recruitment to the sediment during each series was studied by placing 2 boxes $(10 \times 10 \times 4.4 \mathrm{~cm})$ filled with azoic sediment inside and outside each cage. On return to the laboratory each core was divided at depth intervals of $3 \mathrm{~cm}$, and the sediment within each interval was preserved separately in $10 \%$ neutralized formaldehyde. Recruitment trays were preserved in the same way. All samples were washed through a double set of $500 \mu \mathrm{m}$ and $250 \mu \mathrm{m}$ sieves, and the contents of the sieves stained with Rose Bengal. The animals were sorted under a binocular microscope and all, except nematodes and protozoans, were identified to species or larger taxon. Only animals in the 0 to $3 \mathrm{~cm}$ depth interval were compared for predation effects.

The light reduction caused by the predator exclusion cage was determined with a light sensor on land.

\section{RESULTS}

During the experimental period (31/10-78 to $31 / 10$ 79 ) the measured salinity range was $31.6 \%$ to $29.5 \% \mathrm{~S}$. Temperature ranged from $8.8^{\circ} \mathrm{C}$ on $7 / 11-78$ to an observed minimum of $3.2^{\circ} \mathrm{C}$ on $14 / 3-79$ and increased to $8.0^{\circ} \mathrm{C}$ on $31 / 10-79$.

Fig. 1 shows the particle size distribution in the sediment down to a depth of $7 \mathrm{~cm}$ using direct measurements. There is a clear shift in the particle size distribution between 3 to $4 \mathrm{~cm}$ and 4 to $5 \mathrm{~cm}$. Above 4 to $5 \mathrm{~cm}$ the particle distribution centers around $180 \mu \mathrm{m}$; below this depth it shifts to finer particles. The distribution of total carbon, nitrogen and \% water of the sediment at the experimental site is shown in Fig. 2. Values decreased from $0.5,6.4$ and $70 \%$ respectively for the top 0 to $3 \mathrm{~cm}$, to $0.27,3.5$ and $57 \%$ at 6 to $7 \mathrm{~cm}$ depth.

Visual inspection and photographs taken during the experiment gave little indication of any modification of the sediment inside as compared with outside the cages. The inside sediment level was not different from the level outside. Inspection of the cages showed little epigrowth during the experiments; only on 31/10-79 could a few ascidians and some spionid tubes be seen. However, in August 1979 significant epigrowth of spionids was seen. Experiments from this period were not considered. Light reduction by clean cages was $25.5 \%$

ANOVA indicate (Table 1) that corers from different cages can be treated as independant replicates since the variability 'between corers in different cages' is not significant greater than 'between corers within a cage'.

Figs. 3, 4 and 5 show densities of identified faunal groups in cage and control for the 3 periods reported. Ranking the different taxonomic groups in control and 
cage according to abundance in control and testing for the existence of an association between rank in cage and in control (Spearmans $r_{s}$; Siegel, 1956) gives good correlations $\left(r_{s}=0.90,0.93,0.92\right)$ for the 3 periods investigated. This indicates that the gross community structure has not been affected by the cages. However,

Table 1. One way analysis of variance on total number of animals in cores from diffrent cages for each experimental period. NS $=$ Not significant $(p=0.05)$

\begin{tabular}{|cclcc|}
\hline Period 1 & $F=2.7306$ & DF NUM 2 & NS \\
& & DF DENOM 9 & \\
Period 2 & $F=0.5358$ & DF NUM 2 & NS \\
& & DF DENOM 6 & \\
Period 3 & $F=0.1149$ & DF NUM 2 & NS \\
& & DF DENOM 9 & \\
\hline
\end{tabular}
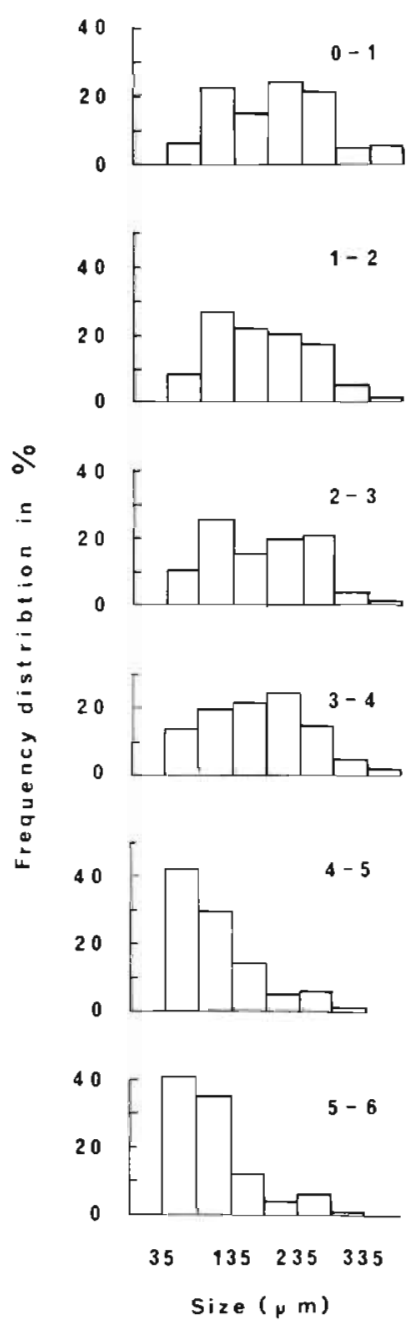

Fig. 1. Size frequency distribution of sediment particles larger than $35 \mu \mathrm{m}$ at different depth intervals. Depth intervals $(\mathrm{cm})$ are indicated. Sampling date 8/2-78. Number of particles counted in each depth interval were 200 to 148 some significant statistical differences in faunal abundance were found. In experiments performed from $31 / 10-78$ to $13 / 3-79$ (Fig. 3) 10 faunal groups out of a total of 15 were more abundant in the cages than in the control region, but only Phyllodocidae, Bivalves and Ostracodes were significantly more abundant. From $14 / 3$ to $12 / 6-79$ (Fig. 4) 13 faunal groups out of a total of 16 were more abundant in the cages than in the control area. In this period only benthic copepods, Paranois sp. and Dorvellidae, were significantly more abundant. In the third period $2 / 9$ to $31 / 10-79$ (Fig. 5) 10 groups out of 14 were more abundant in cages than in controls, here only Phöloe minuta were significantly more abundant. For the whole period 45 comparisons were made between densities of animal groups in cages and control area; in 33 of these, densities were higher inside the cage than in the control area, and in 12 densities were lower inside the cages than in the control areas. The possibility of obtaining 11 or fewer faunal groups with densities higher in the control than in the caged area is less than $7.0 \times 10^{-4}$ (Sign test; Siegel, 1956). This indicates that the results are not a product of random processes but a function of our manipulation.

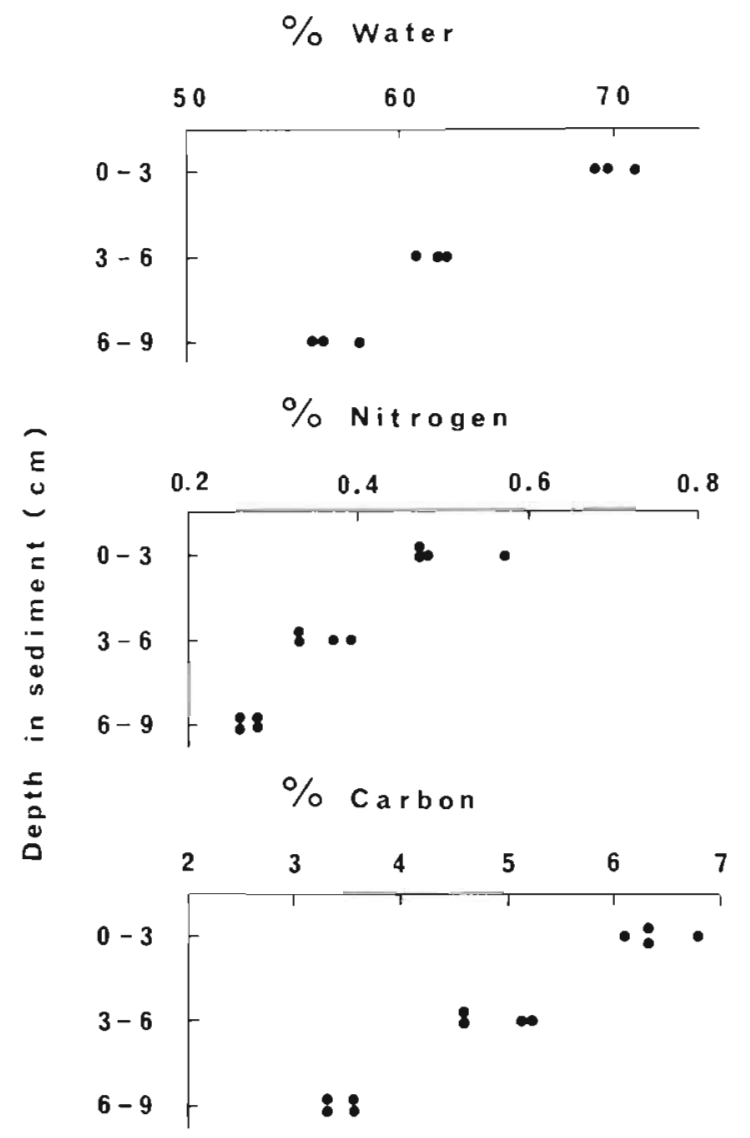

Fig. 2. Percent water, nitrogen and carbon in sediment at different depth intervals. Sediment for water content was collected on 8/7-81, samples for $N$ and $C$ on $11 / 4-80$ 
18

Mar. Ecol. Prog. Ser 11: 15-22, 1983
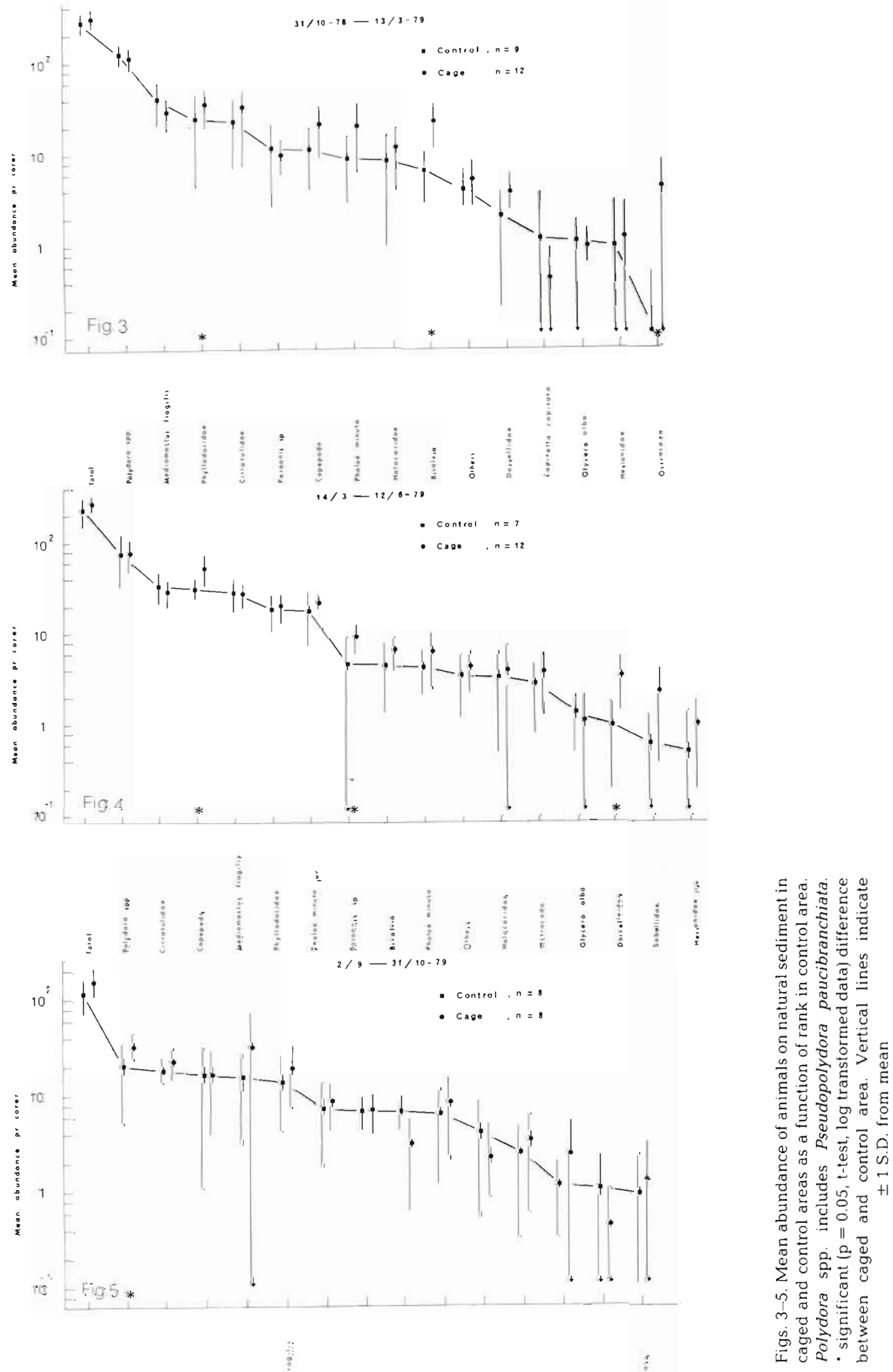
Figs. 6,7 and 8 show the mean abundance in settling trays inside and outside the cages. Ranking the different taxonomic groups in settling trays according to decreasing abundance in the control area, and testing for the existence of a correlation between ranks in cage and control area gives a good correlation $\left(r_{\mathrm{s}}=0.87\right.$, $0.92,0.93$ ) for the 3 periods. This indicates that recolonisation/settling of the different taxa has been proportional in settling-trays inside and outside the cages. For the whole period 49 comparisons were made between abundances of animal groups in settling trays inside and outside the cages; in 24 of these, densities were higher in cages than in control areas. This is near to what one would expect if densities were caused by random processes. Thus the manipulation is of little systematic importance in influencing densities in the settling trays.

Table 2 witnesses that the variation in rank for the different treatments is caused by differences in environmental conditions in settling trays and on natural sediments rather than by cage effects. There was no significant tendency for opportunistic species like Polydora spp. and Capitella capitata to increase in abundance on natural sediment inside the cages. However, results from settling trays clearly indicate that the recruitment potential is available if disturbed sediment is found. This is most evident for C. capitata. In our experiments $83 \%$ of the animals were found in the top $3 \mathrm{~cm}$ of the sediment on 13/3-79. Only Mediomastus fragilis occurred in large numbers deeper than $3 \mathrm{~cm}$ and is not adequately represented by data in the 0 to $3 \mathrm{~cm}$ sediment fraction.

In our samples at least 6 species of spionids were identified. These were Polydora ciliata, P. caulleryi, $P$. socialis, Pseudopolydora paucibranchiata, Prionospio malmgreni and spionidae indet. However, $P$. ciliata and $P$. paucibranchiata accounted for more than $99 \%$ of the individuals. In the settling trays $P$. ciliata accounted for $90 \%$ of the individuals for the total numbers of trays and for the trays collected on 31/1079; a subsample containing 138 individuals consisted entirely of $P$. ciliata. In the natural sediment $P$. paucibranchiata dominated the samples from March (77\%) and June $(96 \%)$, but $P$. ciliata dominated in the samples collected at the beginning of the experiments $31 /$ $10-78(83 \%)$ and at the end of the experiments $31 / 10-$ $79(95 \%)$.

\section{DISCUSSION}

Our experiments were performed to evaluate the effect of epibenthic macropredators on infaunal community structure and abundance in a subtidal habitat. Here, water currents were suspected to be low, resulting in a minimum of sedimentary modifications inside the cages. In high-energy environments caging experiments are most likely to be biased by sedimentary modifications inside the cages (Hulberg and Oliver, 1980). Gray (1981) pointed out that because of the disturbance caused by the mere presence of the cages the species most likely to increase in abundance in caging experiments are the opportunists.

Preparation of the settling trays produced a disturbed sediment, which resulted in enhanced abundance of the classical opportunist Capitella capitata in the trays. Thus numbers were much higher in the settling trays than on the natural sediment both absolute and relative to other members of the fauna. This suggests that if disturbed sediment is available, this species has a recruitment potential sufficient to increase in abundance dramatically within a short period of time. In our experiments C. capitata did not, however, increase in abundance in the natural sedi-

Table 2. Degrees of association (Spearmans $r_{s}$ Siegel, 1956) between rank number of faunal groups found in manipulated samples. Period $1=31 / 10-78$ to $13 / 3-79$; Period $2=14 / 3$ to $12 / 6-79$; Period $3=2 / 9-31 / 10-79$

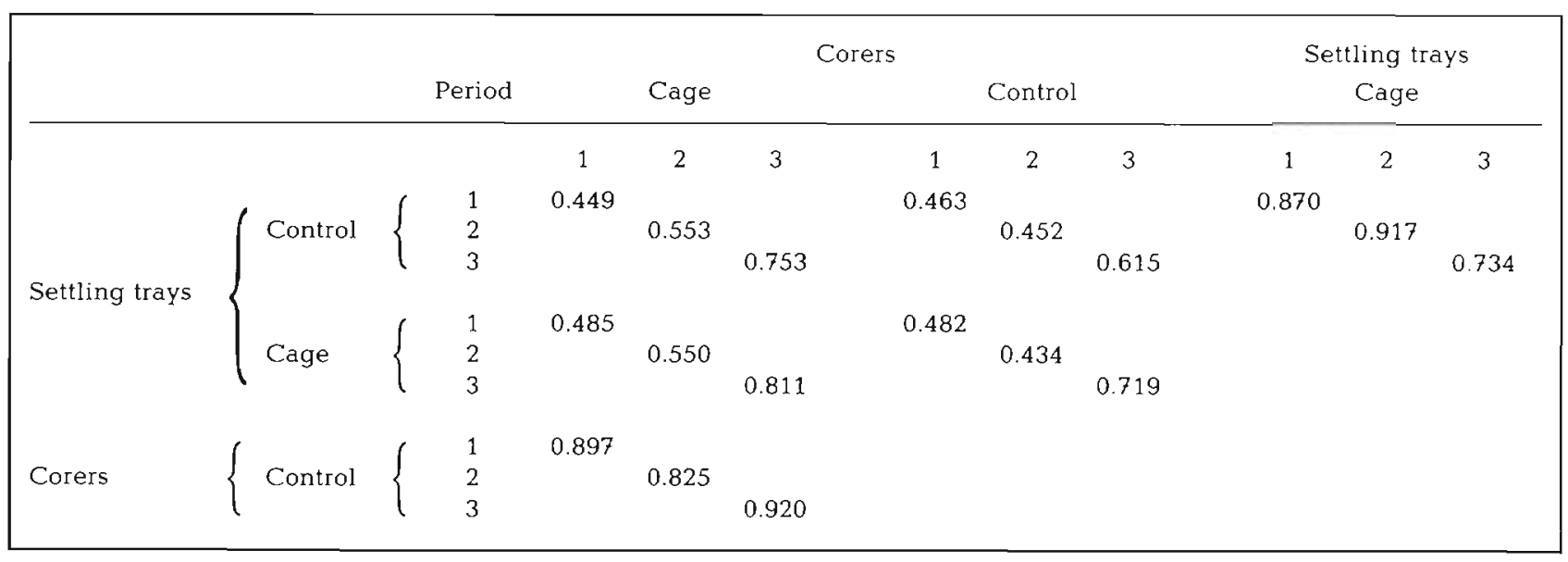



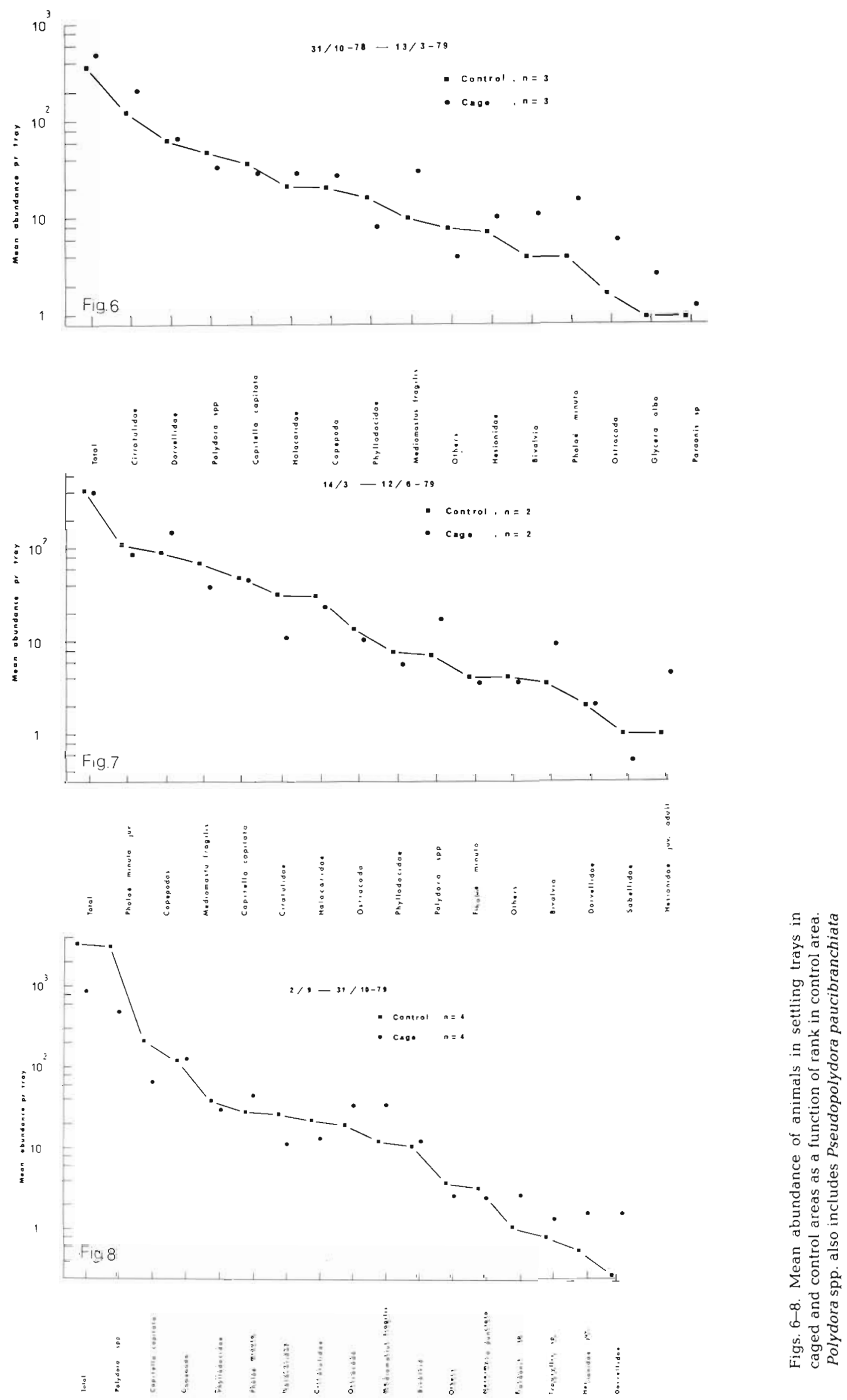
ment within the cages; this suggests that habitat modifications caused by the cages were small.

It is thus believed that the responses found in our experiments are not caused by modification of the sediment inside the cages. However, some modification in physical properties (e.g. light) caused mainly by the cages alone were evident.

Peterson (1979) reviewed exclusion experiments conducted on soft sediments. He concludes that, in general, higher densities occur inside predator exclusion cages than outside. Peterson states that some of this difference is caused by reduced predation pressure. The number of taxonomic groups revealing a positive density difference between caged and control area deviates significantly from random expectation, thus showing an effect of manipulation.

Our results indicate that the density of most faunal groups increased slightly inside the cages, but relatively few increased significantly. However, when performing multiple significance tests there is always the probability of finding spurious (but apparently significant) differences. Where significant differences were found the densities were always highest in the cages. This suggests that the effect of our manipulation dominates possible spurious effects. None of the faunal groups that increased significantly did so consistently for the whole year studied. Thus even if there were effects due to causes other than predators, they were slight. Furthermore, community structure as measured by relative faunal abundance patterns was nearly identical in cage and control areas. Based on these arguments we conclude that predation by epibenthic macropredators was not of fundamental importance in structuring the subtidal sedimentary communities studied in the eutrophicated inner Oslofjord, and only weak indications of predator controlling densities were documented. However, small-sized predators may still be important within the community investigated. Our results are in marked contrast to the large density increase found in most predator exclusion experiments in intertidal and shallow water subtidal habitats (see Peterson, 1979).

Few predator exclusion experiments have been performed in subtidal sediments. Blegvad (1927) conducted experiments in Nissum Bredning, Denmark, at a depth of $5.5 \mathrm{~m}$. He found a dramatic increase in abundance and species numbers inside his experimental boxes. Important fish prey, e.g. Abra alba, increased 5-fold. However, his predation exclusion boxes were heavily covered by fouling organisms and had a trap-like effect on several organisms. Furthermore, the sediment inside the boxes was disturbed due to sieving prior to experimentation. Thus Blegvad's experiments entail serious limitations in evaluating predator effects on the fauna. Arntz (1977) exper- imented at $20 \mathrm{~m}$ depth in the Kiel Bight, Federal Republic of Germany. His results are also difficult to interpret because of unusually high numbers of predators inside the cages. Virnstein $(1977,1978,1979)$ performed several predator exclusion experiments in the subtidal; however, most of his experiments were performed at only $1.5 \mathrm{~m}$ depth. Only Virnstein (1978) experimented on the shallow continental shelf $25 \mathrm{~km}$ offshore from Fort Pierce, Florida (USA) at 33 m, i.e. at a depth comparable to this study. After $2.5 \mathrm{mo}$, infauna density inside his cages had not increased. Virnstein attributed this to the cages not being efficient in excluding predators. Holland et al. (1980) performed experiments in the mesohaline region of the Upper Chesapeake Bay (USA) in a mud habitat at 11 to $12 \mathrm{~m}$ depth. They found little evidence for predators being important in controlling infauna densities, and also in a nearshore sand habitat ( 2 to $3 \mathrm{~m}$ ) predation played a relatively minor role, except during fall. However, in a muddy-sand habitat at 6 to $7 \mathrm{~m}$ predators played a major role, except in winter and early spring. Predator exclusion/inclusion experiments performed by Berge and Hesthagen (1981) in a low-energy area of the eutrophicated Oslofjord showed that epibenthic macropredators did not crop infauna to an extent sufficient to alter faunal composition or reduce abundance discernibly. This contrasts with the general conclusion for predator exclusion experiments on unvegetated mudflats (see Peterson, 1979). In vegetated shallow-water mudflats, habitat exclusion of large epibenthic predators also suggests that predators exert little effect on macrobenthic communities (Peterson, 1979). This finding has partially been attributed to the interference of submerged vegetation with the success of predator foraging (Reise, 1977b). In vegetated habitats current velocities are likely to be reduced by the vegetation, thus the effect of cages on sediment modification is probably less pronounced.

On subtidal sediments relatively few investigations have been conducted. Thus, general conclusions regarding faunal responses cannot be made conclusively by reviewing the literature. However, several experiments seem to suggest that macropredators are of minor importance.

Much of the increased abundance found in predator exclusion experiments is related to increased abundances of opportunists (Virnstein, 1977; Gray, 1981) often found near the sediment surface, and species least affected are those living deep into the sediment (Virnstein, 1977). Disturbance and modification of the sediment caused by cages are most likely to occur in high-energy areas at the sediment surface and least likely to occur below the sediment surface. Thus results from predator exclusion experiments in highenergy areas may have overestimated the effect of 
predators, whereas in areas with limited water movement results are less affected. Thus the relative importance of predation and habitat modification in habitats with high current velocities remains to be established.

Acknowledgements. This investigation is part of $F . O . H$ Project No. 203 under the Norwegian Marine Pollution Research and Monitoring Programme. We wish to thank especially Professor J. S. Gray for support during this study. We further wish to thank J. Frederich Grassle and Richard Nash for comments on the manuscript. We are indebted to several people for diving assistance, foremost Hartvig Christie. Finally we want to thank J. P. Ramberg for assistance in identifying species of Polydora and $P_{\text {seudopolydora. }}$

\section{LITERATURE CITED}

Arntz, W. E. (1977). Results and problems of an 'unsuccessful' benthos cage predation experiment (Western Baltic). In: Keegan, B. F., O'Ceidigh, P. O., Boaden, P. J. S. (eds.) 11 th European Marine Biology Symposium. 'Biology of benthic organisms' Pergamon Press, Oxford, p. 31-44

Berge, J. A. (1980). Methods for biological monitoring: biological interactions in communities of subtidal sediments. Helgoländer Meeresunters. 33: 495-506

Berge, J. A., Hesthagen, I. H. (1981). Effects of epibenthic macropredators on community structure in an eutrophicated shallow water area, with special reference to food consumption by the common goby Pomatoschistus microps. In: Rheinheimer, G., Flügel, H., Lenz, J., Zeitzschel, B. (eds.) 15th European Marine Biology Symposium. Kieler Meeresforsch. Sonderh. 5: 462-470

Blegvad, H. (1927). Om fiskenes konsum av bunndyr. Et forsag med oppvekst ay bunndyr i kasser. Naturen 51: $22-29$

Gray, J. S. (1981). Ecology of marine sediments. Cambridge University Press, Cambridge

Gray, J. S., Mirza, F. B. (1979). A possible method for the detection of pollution-induced disturbance on marine benthic communities. Mar. Pollut. Bull. 10: 142-146

Holland, A. F., Mounthford, N. K., Hiegel, M. H., Kaumeyer K. R., Mihursky, J. A. (1980). Influence of predation on infaunal abundance in upper Chesapeake Bay, USA. Mar. Biol. 57: 221-235

Hulberg, L. W., Oliver, J. S. (1980). Caging manipulations in marine soft bottom communities: importance of animal interactions or sedimentary habitat modifications. J. Fish. Res. Bd Can. 37(7): 1130-1139

Mirza, F. B., Gray, J. S. (1981). The fauna of benthic sediments from the organically enriched Oslofjord, Norway. J. exp. mar. Biol. Ecol. 54: 181-297
Naqui, S. M. Z. (1968). Effects of predation on infauna invertebrates of Alligator Harbor, Florida. Gulf Res. Rep. 2(3): 313-321

Pearson, T. H., Rosenberg, R. (1978). Macrobenthic succession in relation to organic enrichment and pollution of the marine environment. Oceanogr. mar. Biol. A. Rev. 16: 229-311

Peterson, C. H. (1979). Predation, competitive exclusion and diversity in the soft-sediment benthic communities of estuaries and lagoons. In: Leringston, R. J. (ed.) Ecological processes in coastal and marine systems. Plenum Press, New York, p. 233-264

Reise, K. (1977a). Predator exclusion experiments in an intertidal mud flat. Helgoländer wiss. Meeresunters. 30: $63-271$

Reise, K. (1977b). Predation pressure and community structure of an intertidal soft-bottom fauna. In: Keegan, B. F., Ceidigh, P. O., Boaden, P. J. S. (eds.) Biology of benthic organisms. 11th European Symposium on Marine Biology, Galway, October 1976. Pergamon Press, Oxford, p. $513-519$

Reise, K. (1978). Experiments on epibenthic predation in the Wadden Sea. Helgoländer wiss. Meeresunters. 31: 55-101

Reise, K. (1979). Moderate predation on meiofauna by the macrobenthos of the Wadden Sea. Helgolander wiss. Meeresunters. 32: 453-465

Siegel, S. (1956). Nonparametric statistics for the behaviour sciences. McGraw-Hill, Kogakusha Ltd. Tokyo

Virnstein, R. W. (1977). The importance of predation by crabs and fish on benthic infauna in Chesapeake Bay. Ecology 58: $1199-1217$

Virnstein, R. W. (1978). Predator caging experiments in soft sediments: caution advised. In: Wiley, M. L. (ed.) Estuarine interactions. Academic Press, London, p. 261-273

Virnstein, R. W. (1979). Predation on estuarine infauna: response patterns of component species. Estuaries 2 (2): $69-86$

Woodin, S. A. (1974). Polychaete abundance patterns in a marine soft-sediment environment; the importance of biological interactions. Ecol. Monogr. 44: 171-187

Woodin, S. A. (1981). Disturbance and community structure in a shallow water sand flat. Ecology 62(4): 1052-1066

Young, D. K., Buzas, M. A., Young, M. W. (1976). Species density of macrobenthos associated with seagrass: a field experimental study of predation. J. mar. Res. 34: 577-592

Young, D. K., Young, M. W. (1978). Regulation of species densities of seagrass-associated macrobenthos: evidence from field experiments in the Indian River estuary, Florida. J. mar. Res. 36(4): 569-593 